\title{
Carbon Monoxide Effects on Electrophysiological Mechanisms of Ventricular Arrhythmogenesis
}

\author{
Moza M Al-Owais, Chris Peers, Derek S Steele, Arun V Holden and Alan P Benson \\ University of Leeds, Leeds LS2 9JT, UK
}

\begin{abstract}
Increased dissolved carbon monoxide decreases $I_{C a, L}$ $I_{K 1}$ and $I_{K r}$, and increases late $I_{N a}$ currents in rat and guinea pig patch-clamped isolated ventricular myocytes. Action potentials are prolonged.

These effects are reproduced by scaling the currents in the Gattoni et al., 2016 (rat) and Luo and Rudy, 1994 (guinea-pig) cell models.

Using the same scaling of currents in the O'Hara-Rudy (2011) models the endo-, mid-myo- and epi-cardial APD 90 is prolonged. $\mathrm{CO}$ abolishes alternans in endo-, and induces alternans in mid-myo -cardial cell models at cycle lengths $<280 \mathrm{~ms}$.

In the homogenous human ventricular tissue models these $C O$ effects decrease epi-, endocardial conduction velocities from 0.4 to $0.32 \mathrm{~m} / \mathrm{s}$, and increase the widths of the vulnerable windows by $+9 \%,+8 \%$.

In the ventricular wall model (a third each of endo-, mid-myo- and epicardial) $\mathrm{CO}$ increased transmural propagation times from 44 to $55 \mathrm{~ms}$ and maximal difference in propagating APD from 68 to $73 \mathrm{~ms}$.

The computed effects of $\mathrm{CO}$ on human ventricular tissue are pro-arrhythmogenic.
\end{abstract}

\section{Introduction}

Sub-lethal acute or chronic carbon monoxide (CO) poisoning is associated with prolonged QT intervals, increased QT interval dispersion, and increases incidence of arrhythmia and sudden cardiac death [1]. In rat and guinea pig ventricular patch-clamped myocytes increased $\mathrm{CO}$ decreased $\mathrm{I}_{\mathrm{Ca}, \mathrm{L}} \quad \mathrm{I}_{\mathrm{K} 1}$ and $\mathrm{I}_{\mathrm{Kr}}$ and increased late $\mathrm{I}_{\mathrm{Na}}$ currents. CO prolongs cell action potential durations, decreases AP amplitudes and leads and repolarisation failure [2,3].

In guinea-pig epicardial myocytes, with repetitive stimulation at a BCL of $6 s$ the APD is $346 \pm 82.9 \mathrm{~ms}$. In 9 experiments on perfusion with $\mathrm{CO}$ in solution the APD progressively increases $2-4$ fold to $584.3 \pm 82.9$ ms over up to $500 \mathrm{~s}$, leading into repolarization failure. The APD prolongation is reversible up to 300s by the hERG activator [5] NS 1643. This is illustrated in Figure.1.

Table 1. Percentage changes (mean \pm sd) in ionic currents produced by $30 \mu \mathrm{M} \mathrm{CO}[3,4]$.

\begin{tabular}{|c|c|c|}
\hline Current & $\mathrm{I}_{\mathrm{K} 1}$ & Late $\mathrm{I}_{\mathrm{Na}}$ \\
\hline Rat myocytes $-53.2 \pm 3$ & $34.4 \pm 4.3$ & $105.7 \pm 31.1$ \\
\hline HEK293 & $-43.5 \pm 2.3$ & \\
\hline GP myocytes & $-65.2 \pm 4.0$ & \\
\hline
\end{tabular}

We incorporate these $\mathrm{CO}$ produced changes in ionic current magnitudes into populations of human ventricular cell models, and tissue models, to evaluate possible arrhythmogenic mechanisms.
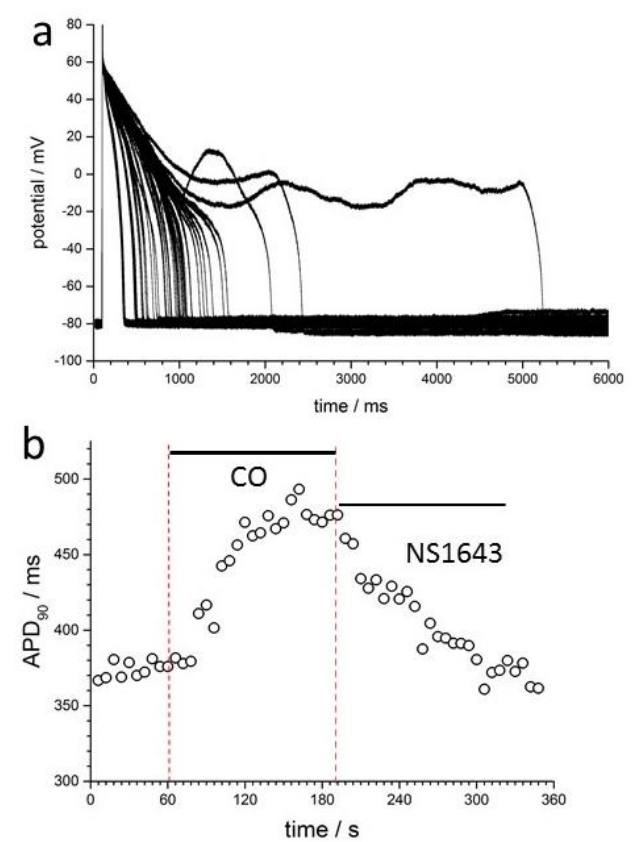

Figure 1. (a) Prolongation of guinea-pig endocardial ventricular myocyte $\mathrm{APD}_{90}$ by exposure to $\mathrm{CO}$. Whole cell recording, $20^{\circ} \mathrm{C}$, periodic stimulation with $\mathrm{BCL}=6 \mathrm{~s}$. (b) Time course of $\mathrm{APD}_{90}$ during exposure to $\mathrm{CI}$ followed by NS1643. 


\section{Methods}

Propagation was modelled by the non-linear partial differential equation:

$$
\partial \mathrm{V} / \partial \mathrm{t}=\nabla(\mathrm{D} \nabla \mathrm{V})-\mathrm{I}_{\text {ion }}
$$

$V / \mathrm{mV}$ is membrane potential, $\nabla$ is a spatial gradient operator, and $t$ is time $/ \mathrm{ms}$. $D$ is the diffusion coefficient $/ \mathrm{mm}^{2} \mathrm{~ms}^{-1}$ that characterizes the electrotonic spread of voltage via local circuit currents, through cell-to-cell coupling by gap junctions, and the extracellular and intracellular resistances. $I_{\text {ion }} / \mu \mathrm{A} . \mu \mathrm{F}^{-1}$ is the total membrane ionic current density and is described by the Gattoni et al [6] Luo \& Rudy [7] or O’Hara \& Rudy [8] models.

In a $1 \mathrm{D}$ model, the type of cell model, its parameters, and diffusion coefficients can change with distance. Such a 1D, heterogenous model for propagation in tissue have been widely applied to model propagation, the rate dependence of APD, the vulnerability to re-entrant arrhythmia effects on the ECG, and cardiac pacemaking. In the ventricular wall model there was a stepwise change in the parameters for between the endo-, mid-myo- and epi-cardial models, each of which occupied a third of the 1-D strand.

Cell models and tissue models were solved with a space step of $\Delta x=0.2 \mathrm{~mm}$, an adaptive time step of $0.01 \mathrm{~ms}$ $0.25 \mathrm{~ms}$. Cell model conductance parameters were Gaussian distributed with a $\pm 5 \%$ standard deviation.

\section{Results}

\subsection{Guinea pig ventricular myocyte}

The effects of $\mathrm{CO}$ on ionic currents (Table 1) prolong the action potentials in the ventricular cell models. In the Gattoni et al. (rat) model this is primarily via late $I_{N a}$, and in the Luo \& Rudy (guinea pig) models primarily via $I_{K r}$. Although $\mathrm{CO}$ produced changes in current in rat cells are used to model the effects of $\mathrm{CO}$, cell and tissue action potential results for the rat model are not presented, as the shape of the guinea pig ventricular action potential is closer to that of the human, and both include $I_{K r}$.

The increase in $\mathrm{APD}_{90}$ is produced by $\mathrm{CO}$ in the guinea pig cell model is seen throughout the dynamic restitution curve, and is greater at shorter BCL, increasing from 10 to $\sim 20 \mathrm{~ms}$ as BCL decreases from 1000 to $200 \mathrm{~ms}$. The computed $\mathrm{APD}_{90} \mathrm{~S}$ of both standard and cell models modified for $\mathrm{CO}$ seen in Fig.2 are much less than the observed $\mathrm{APD}_{90} \mathrm{~S}$ of Fig.1. The restitution curve of Fig.2b does not show any alternans.

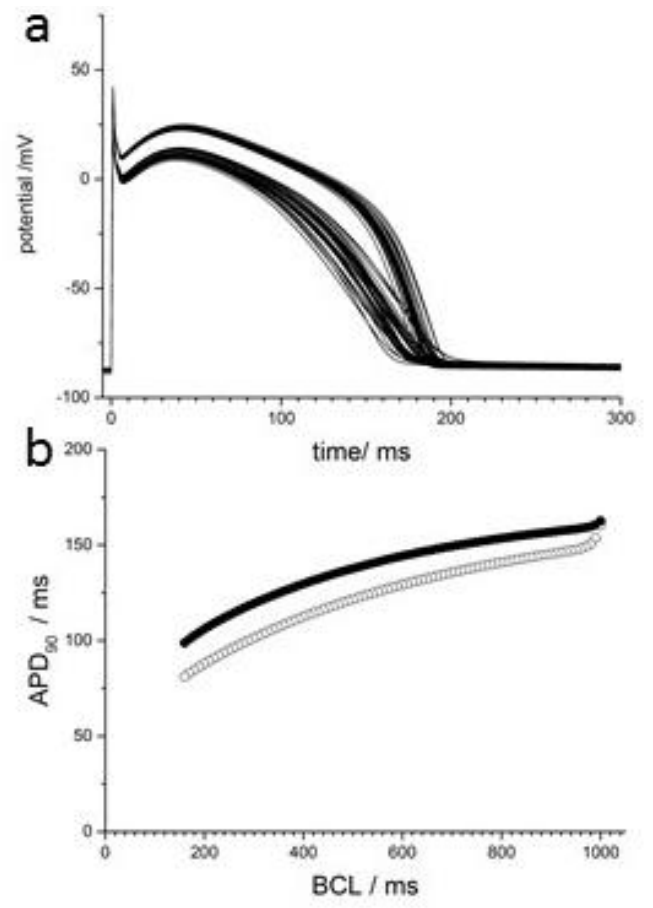

Figure 2. Luo-Rudy epi-cardial cell model, with standard parameters, and conductance parameters modified for $\mathrm{CO}$; note solutions are for $37^{\circ} \mathrm{C}$. (a) last action potentials of 50 cycles, $\mathrm{BCL}=6 \mathrm{~s}$ with $5 \%$ variability in conductance parameters (b) $\mathrm{APD}_{90}$ dynamic restitution curve, $\bullet$ with $\mathrm{CO}$, o with standard parameters. At each cycle length two subsequent $\mathrm{APD}_{90} \mathrm{~S}$ are plotted

\subsection{Guinea pig ventricular tissue propagation}

For homogeneous endo- and epi-cardial ventricular strand models with a constant diffusion coefficient of $0.048 \mathrm{~mm}^{2} / \mathrm{ms}$, the conduction velocity at a BCL of $1 \mathrm{~s}$ is $41.5 \mathrm{~cm} / \mathrm{s}$. For both homogenous strand models this velocity is reduced by $\mathrm{CO}$, to $41.0 \mathrm{~cm} / \mathrm{s}$. The temporal vulnerable window (time interval during repolarization when a 1.5 threshold pulse applied at that point on the strand initiates unidirectional propagation) is constant along the strand and is increased by $\mathrm{CO}$ by less than one ms.

\subsection{Human ventricular myocytes}

In all simulations with the O'Hara \& Rudy (2011) cell models, with a 100 beats at a BCL of $1 \mathrm{~s}$ the effects of $\mathrm{CO}$ are to prolong the action potentials smoothly. With $5 \%$ variability in the conductance parameters the estimated probability density for the $100^{\text {th }}$ action potential, with a 


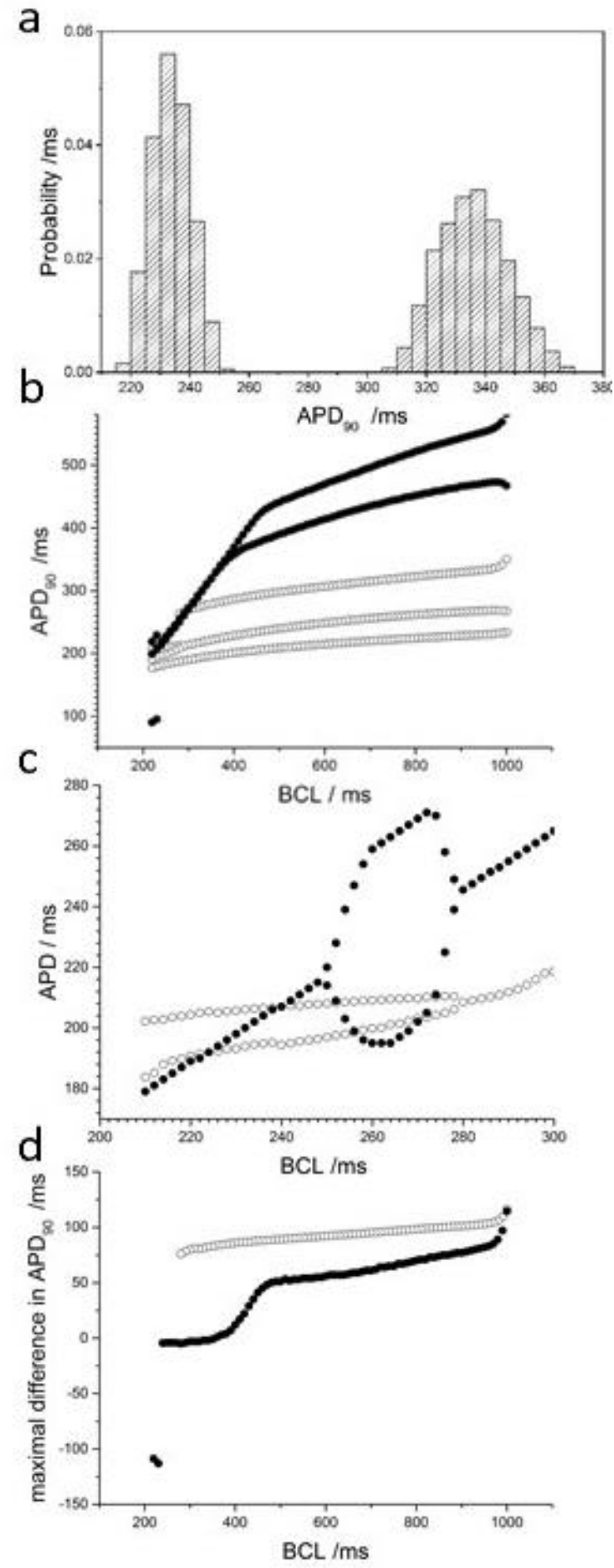

Figure 3. CO effects on O'Hara \& Rudy model properties. (a) Histograms of $\mathrm{APD}_{90}$ of $100^{\text {th }} \mathrm{AP}, \mathrm{BCL}=1 \mathrm{~s}$, with $5 \%$ variability, epicardial cell model. (b) $\mathrm{APD}_{90}$ dynamic restitution curves for $\bullet$ with $\mathrm{CO}$ and $\mathrm{o}$ control for M, epiand endo-cell models (c) magnified, higher resolution view of $\bullet \mathrm{M}$ cell with $\mathrm{CO}$ and $\circ$ control endo-cell models, showing alternans (d) maximal difference in $\mathrm{APD}_{90}$ varies with $\mathrm{BCL} \bullet$ with $\mathrm{CO}$ and $\circ$ control .
BCL of 1s, are unimodal and appear Gaussian (Fig.3a). Endo- and epi-cardial $\mathrm{APD}_{90}$ is prolonged from 267.5 \pm 8.7 , $234.7 \pm 7.3$ to $387.6 \pm 17.9,335.7 \pm 12.3 \mathrm{~ms}$ for the $\mathrm{CO}$ effects on all ion channels, on $I_{K r}$ only to $362.5 \pm 13.9$, $320.5 \pm 11.2$, or $I_{K r}$ in combination with peak and late $\mathrm{Na}$ currents to $407.0 \pm 13.2,334.0 \pm 11.1 \mathrm{~ms}$ at BCL of $1000 \mathrm{~ms}$. Prolongation of the $\mathrm{APD}_{90}$ is seen at all BCL (Fig 3b) Repolarization failure was not observed in these simulations, and CO abolishes alternans in the endo-, and induces alternans in the mid-myocardial cell models (Fig. $3 \mathrm{c})$. The maximal difference between $\mathrm{APD}_{90}$ of the different cell types (between $\mathrm{M}$ and epi-cardial cells) is decreased by $\mathrm{CO}$ at all BCL (fig 3d).

\subsection{Human ventricular propagation}

For homogeneous endo- and epi-cardial ventricular strand models with a constant diffusion coefficient of $0.048 \mathrm{~mm}^{2} / \mathrm{ms}$ (that gives a transmural activation time of $40 \mathrm{~ms}$ for a $16.6 \mathrm{~mm}$ strand paced at $0.5 \mathrm{~Hz}$ ) the conduction velocity at a BCL of $1 \mathrm{~s}$ is $41.2 \mathrm{~cm} / \mathrm{s}$. For both homogenous strand models this velocity is reduced by $\mathrm{CO}$, to $32.7 \mathrm{~cm} / \mathrm{s}$. The temporal vulnerable window for the homogeneous endo- and epi-cardial ventricular strand models are between 1 and $2 \mathrm{~ms}$, and $\mathrm{CO}$ increases them by 3 and $8 \%$ i.e. the computed change has little biomedical consequence.

Ventricular tissue is heterogeneous, and a cartoon 1-D representation of the ventricular wall is by equal thirds of endo-, mid-myo- and epi-cardial cells. In such a model the vulnerable window varies with position and is asymmetric. In the ventricular wall model the space-time integral between the start and end curves provide an index of wall vulnerability. The effect of $\mathrm{CO}$ is to increase this from 958 to $990 \mathrm{~mm} . \mathrm{ms}$ i.e. only a few \%.

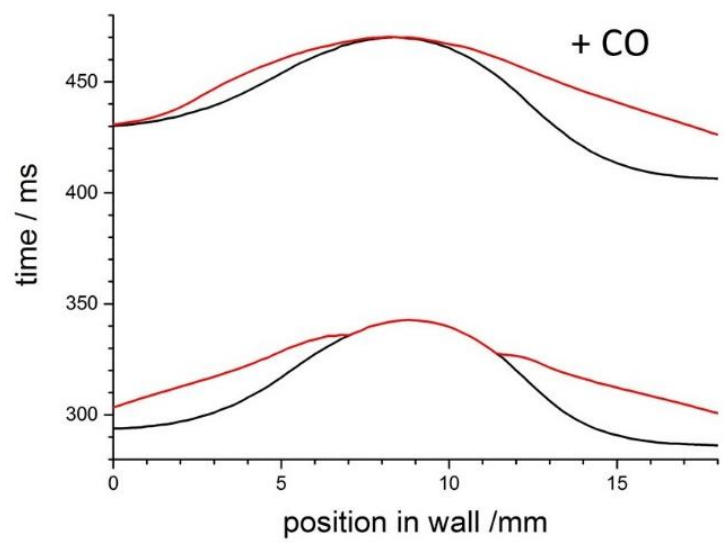

Figure 4. Start (black) and end (red) of vulnerable window in 1D ventricular wall model with equal thirds of epi-, midmyo- and epi-cardial cell models. 


\section{Conclusions}

The patch and isolated cell experiments show dramatic effects of $\mathrm{CO}$ on cell electrophysiology, with large changes in action potential duration, leading to repolarization failure. This would be expected to be strongly arrhythmogenic, and so provide a plausible mechanism for the increased incidence of arrhythmia seen in chronic, low level exposure to CO. However, these large effects are not seen in the guinea pig ventricular cell model, where the prolongation of the action potential is much less. The biophysical experiments were performed at room temperature $\left(\sim 21^{\circ} \mathrm{C}\right)$ whereas the models were constructed for body temperature. Real mechanisms, observed at low temperature, may not be effective at body temperature. The effects of temperature on ventricular action potential duration [9] are well known, with $\mathrm{APD}_{90}$ being extended 23 fold by a $10^{\circ}$ decrease in temperature. Temperature appears explicitly in cardiac cell excitation models (as in $\mathrm{RT} / \mathrm{FZ}$ ) and implicitly via the $\mathrm{Q}_{10}$ for the voltage diffusion coefficient and the single and maximal channel conductances $\left(\mathrm{Q}_{10} \sim 1.2-1.5\right)$, for channel gating kinetics $\left(\mathrm{Q}_{10} \sim 2-4\right)$ and of exchange pumps $\left(\mathrm{Q}_{10} 3-3.5\right)$ and crossbridge cycling transition rates $\left(\mathrm{Q}_{10} \sim 6\right)[10]$. The $\mathrm{Q}_{10}$ effect is to multiple the parameter by $\left(\mathrm{Q}_{10}\right)^{((\mathrm{T}-37) / 10)}$.

Arrhythmogenic effects are apparent in the human cell and tissue models, both as direct result of the $\mathrm{CO}$ effects on ionic currents, and indirectly, via changes in propagation velocity.

\section{References}

[1] Satran D et al. Cardiovascular manifestations of moderate to severe carbon monoxide poisoning. J. A. Coll. Cardiol. 1998; $45: 1513-1516$.
[2] Dallas ML et al. Carbon monoxide induces cardiac arrhythmia via induction of the late $\mathrm{Na}^{+}$current. Am.J. Respir. Crit. Care Med. 2012;186:648-656.

[3] Al-Owais MM et al. A key role for peroxynitrite-mediated inhibition of cardiac ERG (Kv11.1) $\mathrm{K}^{+}$channels in carbon monoxide-induced proarrhythmic early afterdepolarisation FASEB J 2017; 31: 4845-4854.

[4] Liang $\mathrm{S}$ et al. Carbon monoxide inhibits inward rectifier potassium channels in cardiomyocytes. Nature Communications 2014; 5:4676.

[5] Peitersen T. et al. Computational analysis of the effects of the hERG channel opener NS1643 in a human ventricular cell model. Heart Rhythm 2008;5:734-741.

[6] Gattoni $S$ et al. The calcium-frequency response in the rat ventricular myocyte: an experimental and modelling study. J. Physiol. 2016; 594: 4193224.

[7] Luo CH, Rudy Y. A dynamic model of the cardiac ventricular action potential. I Simulations of ionic currents and concentration changes. Circ Res. 1994;74: 1071-1096.

[8] O'Hara T, Virag L, Varro A, Rudy Y (2011) Simulation of the undiseased human cardiac ventricular action potential: model formulation and experimental validation. PLOS Computational Biology 7, e1002061

[9] Bjornstad $\mathrm{H}$ et al. Effects of temperature on cycle length dependent changes and restitution of action potential duration in guineas pig ventricular muscle. Cardiovasular Res. 1993;27:946-950.

[10]Tsien RW, Noble D. A transition state theory approach to the kinetics of conductance changes inexcitable membranes. J. Membrane Biol. 1969:1, 248-273.

Address for correspondence.

Arun V Holden

School of Biomedical Sciences,

University of Leeds,

Leeds, LS2 9JT, UK

a.v.holden@leeds.ac.uk. 